\title{
MIGRAÇÃO E SAÚDE DE BRASILEIROS RESIDENTES EM LISBOA
}

\author{
Lyria Maria dos Reis ${ }^{1}$ \\ Natália Ramos ${ }^{2}$
}

\section{RESUMO}

As migrações internacionais são uma constante no mundo globalizado e os brasileiros também fazem parte deste grupo de indivíduos que se desloca para diferentes países e continentes, muitas vezes em busca de melhores condições de vida. Portugueses e brasileiros sempre cruzaram o oceano Atlântico e, atualmente, mais de cem mil brasileiros vivem regularmente em Portugal. A mudança de um país para outro provoca alterações no contexto biopsicossocial dos indivíduos que deixam o seu meio conhecido e vão de encontro a um meio novo. Um dos aspectos importantes a ser investigado em contexto migratório é o efeito que a migração e a condição de "ser imigrante" podem provocar nestes sujeitos, principalmente na sua saúde. Esta comunicação tem como objetivo apresentar alguns dos resultados de uma investigação sobre determinantes da saúde de imigrantes brasileiros, homens e mulheres residentes na região de Lisboa, desenvolvida no âmbito de um projeto de doutoramento em Psicologia realizado na Universidade Aberta de Lisboa. A investigação tem como objetivo geral conhecer e compreender a situação de imigrantes brasileiros residentes em Lisboa, a sua relação com a saúde e a doença, o seu processo migratório e os possíveis efeitos deste sobre a sua saúde, os seus estilos de vida e qualidade de vida. Para o estudo empírico foram inquiridos 120 brasileiros (67 mulheres e 53 homens) com idades entre os 19 e 64 anos, residentes em Portugal há mais de 1 ano e que, após esclarecimento, concordaram em colaborar com a pesquisa. Os inquéritos foram analisados utilizando estatística descritiva e análise temática de conteúdo. Os principais resultados encontrados evidenciaram que a maioria dos entrevistados apresenta boa saúde embora tenha ocorrido uma diminuição na procura de cuidados de saúde, principalmente ao nível preventivo. Consideramos necessário aumentar a informação direcionada aos imigrantes quanto aos seus direitos para uma melhor adaptação e integração no país de acolhimento, bem como para uma saúde e qualidade de vida.

Palavras-chave: Imigração e saúde. Imigrantes brasileiros. Imigração em Portugal. Determinantes da saúde.

\footnotetext{
${ }^{1}$ Mestre em Comunicação em Saúde (Universidade Aberta-UAb) e Doutoranda em Psicologia (UAb). Investigadora do CEMRI-UAb - email: lyriareis@ gmail.com

${ }^{2}$ Professora Associada da Universidade Aberta de Lisboa; Coordenadora do GI. Saúde, Cultura e Desenvolvimento, CEMRI, UAb - email: natalia@uab.pt
} 


\section{ABSTRACT}

International migration is a constant in the globalized world and the Brazilians are also part of this group of individuals who move to different countries and continents, often in search of better living conditions. Portuguese and Brazilians have crossed the Atlantic Ocean and, at this time, over one hundred thousand Brazilians lives in Portugal, $25.3 \%$ of the immigrants legalized by the Foreign Nationals and Borders Service. The change from one country to another causes changes in the biopsychosocial context of individuals who leaves their familiar environment and goes to live in a new place. One of the important factors to be investigated in migratory context aspects is the effect that migration and the condition of being "immigrant" can cause to these persons, particularly on their health. This paper aims to present some of the findings on health determinants of Brazilian immigrants, men and women living in the Lisbon area, $\mathrm{d}$ an investigation developed in a doctoral project in psychology at the "Universidade Aberta" in Lisbon. The research aims to know and understand Brazilian immigrants in Lisbon, its relationship to health and disease, their migration process and the possible effects of migration on their health, their lifestyle and quality of life. For the empirical study we interviewed 120 Brazilians (67 women and 53 men) aged 19 to 64, living in Portugal over one year who agreed to participate in the study. The surveys were analyzed using descriptive statistics and thematic content analysis. The main findings showed that the majority of respondents have good health although there was a decrease in the demand for health care, especially at preventive level. We consider that is necessary to increase information targeted to immigrants about their rights to a better adaptation and integration in the host country.

Keywords: Immigration and health; Brazilian immigrants; Immigration in Portugal; Determinants of health. 


\section{Introdução}

As migrações fazem parte da história da humanidade e são uma constante no mundo contemporâneo. De acordo com as Nações Unidas o número total de migrantes internacionais tem aumentado no mundo. Em 1990 eram cerca de 154 milhões e em 2013 já são 232 milhões o número de pessoas que deixou o seu país para viver em outro (UNGA, 2013), sendo que uma grande parte são mulheres, ou seja metade dos migrantes internacionais.

Um dos aspectos importantes quando se estudam as migrações e, principalmente os migrantes, são os processos de adaptação em contexto migratório e os efeitos que esses movimentos podem causar na saúde destes indivíduos. Quando um indivíduo deixa o seu país, deixa para trás todo o seu mundo conhecido e aprendido desde a infância para ir de encontro ao novo, ao desconhecido, e terá que reaprender diversos aspectos da vida quotidiana para a sua completa adaptação biopsicossocial.

Este texto tem como objetivo apresentar alguns resultados de uma investigação de doutoramento em Psicologia, sobre determinantes da saúde em contexto migratório, de imigrantes brasileiros residentes na região de Lisboa, realizada na Universidade Aberta em Lisboa. A investigação teve como objetivo geral conhecer e compreender a situação de imigrantes brasileiros residentes nesta região de Portugal, a sua relação com a saúde e a doença, o seu processo migratório e os possíveis efeitos deste sobre a sua saúde, os estilos de vida e qualidade de vida analisados comparativamente (pré e pós migração) através das crenças e comportamentos face à saúde e a doença, a inserção no contexto de saúde brasileiro e português, os estilos de vida adotados em Portugal e a qualidade de vida desta comunidade. A investigação procurou analisar os diversos fatores determinantes da saúde em 
contexto migratório, relacionados às doenças crónicas não transmissíveis.

Este artigo discorrerá sobre a emigração brasileira, a imigração brasileira em Portugal e também sobre a relação dos temas migração e saúde. Em seguida apresentará alguns dos principais resultados do estudo empírico realizado e para finalizar, apresenta algumas considerações gerais sobre o tema.

\section{Emigração brasileira}

A partir dos meados dos anos 50 do século XX, o Brasil, considerado um país de imigrantes, começou também a fazer parte do grupo de países de emigrantes. Nessa época, brasileiros originários das regiões

Norte, Nordeste e Sudeste do país começaram a emigrar para o Paraguai, para trabalhar na derrubada da mata e nas plantações comerciais de hortelã. Posteriormente, os brasileiros dos estados da região Sul, deixavam pequenas propriedades de terra no Brasil e iam para o Paraguai com o objetivo de adquirir maiores extensões de terra (Zamberlam \& Corso, 2007).

Outro destino migratório importante na emigração brasileira são os Estados Unidos. De acordo com Siqueira (2008) o início da emigração de brasileiros de Governador Valadares para os Estados Unidos deu-se no ano de 1964, com um grupo de 17 jovens que foram para este país com visto de trabalho, configurando-se como os pontos iniciais da rede que possibilitou o fluxo valadarense para os Estados Unidos (Siqueira, 2008).

Nos anos 1980, período considerado pelos economistas como a década perdida, ocorreu um aumento do fluxo de brasileiros que decidiram buscar outros países e continentes para viver. Entre os países mais procurados pelos brasileiros estavam os Estados Unidos, o Paraguai e 
o Japão. Na Europa, Portugal, Espanha, Itália e Reino Unido se destacavam como países de acolhimento desses brasileiros.

De acordo com estimativas do Ministério das Relações Exteriores do Brasil, no final do ano de 2010 havia pouco mais de 3 milhões de brasileiros residentes no exterior (Brasil-MRE, 2011). Essas estimativas foram feitas com base em consultas às Embaixadas e Consulados brasileiros no estrangeiro. A América do Norte era a região que detinha a estimativa de maior número de brasileiros no exterior com um total de pouco mais de 1.400 .000 brasileiros. Em seguida a Europa com cerca de 900.000, a América do Sul com cerca de 400.000 e também a Ásia com 240.000 brasileiros. Entre os países mais procurados por brasileiros estavam os Estados Unidos (1.388.000), Japão (230.552), Paraguai (200.000), Reino Unido (180.000), Espanha (158.761) e Portugal (136.220) (Brasil-MRE, 2011).

Segundo o Censo realizado no Brasil em 2011 e de acordo com a metodologia utilizada, o número de brasileiros residentes no exterior aproxima-se de 500.000 pessoas. Os países com maior número de brasileiros residentes eram os Estados Unidos (117.104), Portugal (65.969), Japão (36.202), Itália (34.652) e Reino Unido (32.270).

As diferenças no número de brasileiros residentes no exterior de acordo com as estimativas e o Censo são explicadas devido à metodologia utilizada pelo Instituto Brasileiro de Geografia e Estatística (IBGE, 2011) que perguntava se algum morador daquela residência estava vivendo no exterior, portanto só eram contadas as pessoas que tinham deixado parte da família no Brasil e não as que emigraram com toda a família.

Após a crise económica vivida pelos Estados Unidos e também por diversos países europeus, incluindo Portugal, muitos brasileiros regressaram ao Brasil. 


\section{Imigração brasileira em Portugal}

Devido às relações históricas entre Portugal e Brasil, sempre houve deslocação de brasileiros e portugueses entre esses dois países (Machado, 2006), em alguns momentos indo mais portugueses para o Brasil, como desde finais do século XIX até meados dos anos 60 no século XX e, em outros momentos, mais brasileiros procuraram Portugal como destino migratório. $\mathrm{O}$ aumento do fluxo de brasileiros para Portugal começou como contracorrente migratória, com o retorno de portugueses imigrantes no Brasil, os chamados "brasileiros" em Portugal. Esses "brasileiros" regressaram principalmente para a região norte e centro do país, de onde tinha ocorrido grande parte das migrações para o Brasil.

A partir dos anos 1980, começaram também a chegar a Portugal imigrantes brasileiros da classe média, indivíduos que, descontentes com a situação económico financeira do Brasil, decidiram emigrar. Muitos destes imigrantes brasileiros em Portugal vieram também para o país, devido à sua ascendência portuguesa. Outros brasileiros da classe média, com formação superior emigraram para Portugal nesse período devido a existência de oferta de trabalho e uma demanda por profissionais qualificados em determinadas áreas de especialização. Nos anos 1990 Portugal encontrava-se em pleno crescimento e desenvolvimento após a sua entrada na Comunidade Europeia no ano de 1986, o que atraiu muitos imigrantes. Esse movimento tem sido considerado como a primeira vaga migratória de brasileiros para Portugal onde incluíam-se os profissionais liberais, profissionais de marketing, publicidade e propaganda, cirurgiões dentistas, entre outros (Machado, 2007).

Na década de 90 e também nos primeiros anos do século XXI, devido a diversos fatores, entre eles a dificuldade de se conseguir visto para os 
Estados Unidos, a não necessidade de visto para brasileiros entrarem em Portugal como turista e a facilidade da língua portuguesa, verificou-se um aumento do fluxo de brasileiros para Portugal, assim como, um aumento da diversidade de áreas de inserção destes indivíduos no país. A partir de 1998, ocorreu também um aumento do contingente de brasileiros com menores qualificações e que ocuparam postos de trabalho menos diferenciados, tais como o setor da construção civil e a restauração. Essa tem sido considerada como uma segunda vaga migratória de brasileiros em Portugal, ou seja, os migrantes brasileiros que chegaram ao país após o ano de 1998 (CBL, 2004).

Os brasileiros em Portugal desempenham uma grande variedade de atividades laborais desde trabalhos indiferenciados e mal remunerados até funções bastante qualificadas e muito bem remuneradas, o que reflete a grande diversidade socioeconómica e cultural desta comunidade. Além dos profissionais mais qualificados da primeira vaga (cirurgiões-dentistas, engenheiros, profissionais de marketing, entre outros) os brasileiros também se dedicam a atividades no âmbito da restauração, da construção civil e do comércio. Na chamada segunda vaga migratória vieram para Portugal brasileiros de diversos níveis de escolaridade mas, em maior número, aqueles com menores habilitações académicas.

De acordo com as estimativas do Ministério das Relações Exteriores do Brasil, Portugal concentra a sexta maior comunidade de brasileiros residentes no exterior (Brasil-MRE, 2011). De acordo com o relatório do Serviço de Estrangeiros e Fronteiras (SEF, 2013), referente ao ano de 2012, residem em Portugal 417.042 cidadãos estrangeiros, entre os quais, $25,3 \%$ são brasileiros, considerada a maior comunidade imigrante desde o ano de 2007. Atualmente, o total de brasileiros com situação regularizada é de 105.622 indivíduos sendo 44.127 homens $(41,8 \%)$ e 61.495 mulheres $(58,2 \%)$. Contudo, foi o ano de 2010 que 
registrou o maior número de brasileiros no país, atingindo o total de 119.363 cidadãos, sendo 52.478 homens (44\%) e 66.885 mulheres $(56 \%)$.

Desde então tem havido uma ligeira diminuição do número de imigrantes desta comunidade em virtude da crise económica que Portugal tem vivido recentemente o que tem ocasionado a emigração de brasileiros de Portugal para outros países europeus e, de acordo com o SEF (2013) o retorno de alguns brasileiros para o Brasil, mas também devido à atribuição da nacionalidade portuguesa. Um cidadão estrangeiro residente em Portugal que adquire a nacionalidade portuguesa deixa de ser incluído pelo SEF no número total de imigrantes desta nacionalidade. No ano de 2012 foram emitidas 5.006 certidões de nacionalidade a cidadãos brasileiros (SEF, 2013).

Desde o ano de 2003, foi possível observar uma feminização da imigração brasileira em Portugal. De acordo com o último Censo realizado no país, em 2011, os brasileiros residentes constituíam um total de 109.787 pessoas. A evolução da população brasileira residente em Portugal, de acordo com o SEF, pode ser verificada no gráfico 1, abaixo apresentado.

Gráfico 1: Número de brasileiros com situação regularizada junto ao SEF, 2000-2012.

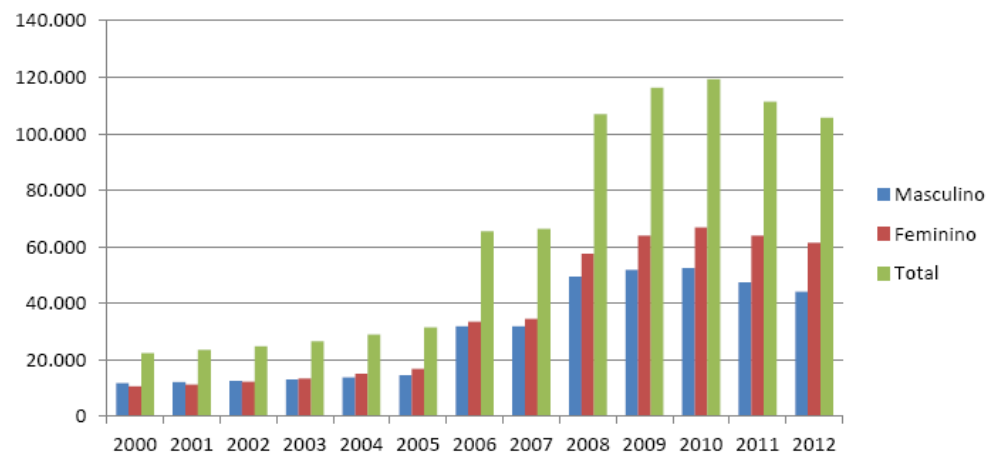

Fonte: Gráfico construído pelas autoras a partir dos Relatórios do SEF de 2000 e $2006-2013$ 


\section{Migração e Saúde}

De acordo com Ramos, "a migração constitui um processo complexo, contraditório, bipolar, uma experiência de perda, ruptura, mudança, vivenciada pelo indivíduo de uma forma mais ou menos traumatizante ou harmoniosa, segundo os seus recursos psicológicos e sociais, as características da sociedade e as condições de acolhimento do país receptor" (Ramos, 2004, p. 255).

O processo migratório envolve mudanças na vida das mulheres e dos homens imigrantes, mudanças essas que poderão ser mais ou menos importantes e/ou traumáticas dependendo de diversos fatores. Muitas mudanças biológicas, físicas, psicológicas, sociais, familiares, culturais e políticas ocorrem na vida do imigrante e as mesmas podem influenciar a sua saúde e qualidade de vida. Diversos autores relatam que os imigrantes são um grupo com uma maior vulnerabilidade às doenças ou a outros problemas de saúde (Carballo, Divino \& Zeric, 1998; Ramos, 2004, 2008).

De acordo com a Organização Mundial da Saúde (OMS), a saúde é o completo bem-estar físico, mental e social e não apenas a ausência de doença ou enfermidade. A saúde é um direito básico fundamental para todas as pessoas, inclusive migrantes, constante no $25^{\circ}$ artigo, item 1 da Declaração Universal dos Direitos Humanos onde "Toda a pessoa tem direito a um nível de vida suficiente para lhe assegurar e à sua família a saúde e o bem-estar, principalmente quanto à alimentação, ao vestuário, ao alojamento, à assistência médica e ainda quanto aos serviços sociais necessários..." (ONU, 1948).

Os processos migratórios e principalmente as migrações internacionais alteram os contextos sociais e culturais de inserção dos indivíduos e também os seus estilos de vida. Essas modificações processam-se em todos os sentidos da vida dos imigrantes. Em geral, todas as pessoas 
buscam adaptar-se ao nível biológico, psicológico, social e cultural ao contexto em que se encontram. Esse processo denominado de aculturação define-se como o conjunto de transformações culturais resultantes dos contatos contínuos e diretos entre dois grupos culturais distintos (Ramos, 2004, p. 257).

Os migrantes necessitam adaptar-se ao novo mundo e às novas exigências. A aculturação quando relacionada à saúde poderá ser mais ou menos facilitada e harmoniosa ou problemática e dependerá de diversos fatores relacionados ao processo migratório em si (condições e motivos em que se efetua a migração), às capacidades individuais e coletivas de adaptação, tanto ao nível biológico, como psicológico e social e ainda, relacionados às condições prévias existentes no país de origem e às condições encontradas no país de acolhimento, incluindo as políticas de acolhimento relativas aos imigrantes. O processo de adaptação e aculturação ocorrerá de diferentes formas para cada indivíduo e grupo.

Outra questão importante a ser investigada em contexto migratório são os fatores determinantes da saúde tais como: os aspectos biológicos (idade, sexo, fatores genéticos); os fatores psicológicos (tipos de personalidade, capacidades de resiliência e adaptação); os estilos de vida adotados (hábitos e comportamentos relacionados à saúde tais como tabagismo, consumo de bebidas alcoólicas, consumo alimentar e prática de exercícios físicos); o capital social e as redes sociais e comunitárias (que dão suporte social e entreajuda); os aspetos socioeconómicos individuais (condições económicas e sociais de educação, habitação e trabalho) e coletivos, como a existência de saneamento básico, existência e acesso a educação, emprego, políticas sociais inclusivas; a existência e o acesso aos serviços sociais e de saúde (Ramos, 2004, 2008, 2009). 
Em contexto migratório, o indivíduo migrante sai do seu mundo conhecido e vai de encontro ao novo, desconhecido, onde tem que reaprender regras e costumes e reconstruir relações. O imigrante terá que conhecer e compreender o novo meio e cultura em que viverá e dessa forma como deverá reagir e se comportar dentro desse novo contexto social e cultural. Para além dos determinantes da saúde, o processo saúde-doença em contexto migratório está intimamente relacionado aos aspectos comunicacionais, cognitivos e de perceção individual, a estereótipos, preconceitos e discriminação (Ramos, 2010, 2012), e aos processos e capacidade individual e coletiva de adaptação ao novo ambiente e à nova cultura. Os processos de adaptação em contexto migratório são complexos, interrelacionais e multidimensionais e poderão influenciar a saúde de uma forma geral, isto é, tanto ao nível da saúde física, como ao nível da saúde mental.

Os diversos fatores do contexto e hábitos de vida do imigrante, tanto aqueles trazidos do país de origem, como os que farão parte da nova vida do indivíduo, influenciarão o modo como este perceberá o mundo a sua volta e como este se comportará no seu dia-a-dia e poderão influenciar a sua saúde. De acordo com Ramos (2004) a percepção é o processo pelo qual o indivíduo seleciona, avalia e organiza os estímulos vindos do mundo exterior. As migrações provocam alterações nos contextos de integração e adaptação dos indivíduos e influenciam as representações e vivências sobre saúde e doença entre os imigrantes.

A auto-percepção sobre o estado de saúde é um importante indicador para avaliar a saúde dos indivíduos e dos grupos. É um indicador construído social e culturalmente pela própria condição de saúde individual e pelo mundo que nos rodeia, sendo assim, uma construção biopsicossocial e cultural de cada indivíduo acerca de sua saúde. Em situação migratória, o contexto em que vive o migrante poderá igualmente influenciar a sua percepção sobre o seu estado de saúde, 
assim como os fatores que influenciam a saúde. Em geral, diversas variáveis como o género, a idade, as (in)capacidades físicas, o nível de escolaridade e de renda poderão influenciar a percepção sobre o estado de saúde. Em contexto migratório, alguns fatores relacionados à migração em si, poderão também influenciar a percepção sobre os fatores que afetam a saúde. Muitas vezes o desconhecimento do modo de funcionamento dos serviços em geral e particularmente sobre os serviços de saúde, bem como o tipo de atendimento nestes serviços poderá fazer com que as pessoas deixem de buscar atendimento (Ramos, 2004, 2012). Os motivos que levaram um indivíduo a migrar também poderão influenciar as suas percepções e influenciar no desenvolvimento de novos comportamentos no país de acolhimento.

No estudo VIGITEL realizado pelo Ministério da Saúde do Brasil em 2011 (Brasil-MS, 2011), no conjunto da população adulta, 4,8\% das pessoas avaliaram o seu estado de saúde como mau ou muito mau sendo 6,2\% das mulheres e 3,1\% dos homens. Em Portugal, estudando a população autóctone no ano de 2002, Cabral (2003) observou que 49,4\% consideravam o estado de saúde como bom e cerca de $11 \%$ consideravam a saúde em mal estado. No estudo de Dias, Paixão, Branco e Falcão (2008) realizado em Portugal, a percepção de saúde "boa ou muito boa" foi mais frequente entre os imigrantes $(62,8 \%)$ do que entre os portugueses $(48,4 \%)$. Estes autores também observaram que a apreciação positiva da saúde entre os imigrantes foi diminuindo conforme aumentava o tempo de permanência no país mas mantendose sempre mais alta que entre os cidadãos nacionais. Totalizavam $6,8 \%$ os imigrantes que consideravam o seu estado de saúde "mau ou muito mau" enquanto esse valor era de $15,9 \%$ para os portugueses e eram os homens que consideravam um estado de saúde melhor que as mulheres (Dias et al, 2008). Serrano-Gallardo, Díaz-Olalla, Otero e Bolumar (2010) realizaram uma investigação comparativa sobre a percepção do estado de saúde na população autóctone e imigrante em Madri. Nos 
resultados encontraram cerca de $14,2 \%$ dos imigrantes e $17,0 \%$ dos autóctones que perceberam um estado de saúde mau ou regular, sendo que os autóctones e as mulheres perceberam um estado de saúde mau ou regular em maior percentagem que os imigrantes.

Outro importante determinante da saúde dos indivíduos em geral e também dos imigrantes em particular é o acesso e utilização dos serviços de saúde que, em geral são influenciados pela migração. Para Ramos (2004, 2012), a migração influencia o modo de utilização dos cuidados e serviços de saúde e sociais, bem como os factores culturais e comunicacionais. A busca por cuidados e serviços de saúde por parte dos imigrantes, para além de suas necessidades preventivas e curativas em saúde, também sofre influência de sua cultura de origem, do modo como utilizavam os serviços de saúde no país de origem, de suas crenças e práticas, da sua condição socioeconómica e também do conhecimento que têm da cultura, da língua, do modo de funcionamento dos serviços, nomeadamente de saúde, e da existência de redes no país de acolhimento.

As barreiras percebidas pelos imigrantes para acesso aos serviços de saúde são diversas. Entre essas temos as barreiras físicas propriamente ditas (a distância dos serviços de saúde), as barreiras socioeconómicas e também as dificuldades de comunicação intercultural. Messias (2002) investigou as representações dos recursos, práticas e perspectivas de saúde transnacionais na narrativa de mulheres brasileiras imigrantes nos Estados Unidos. Os resultados da pesquisa indicaram que, quando cuidam da sua saúde, essas mulheres imigrantes brasileiras baseiam-se, muitas vezes, numa combinação de recursos pessoais e coletivos transnacionais para resolução dos seus problemas de saúde e, embora demonstrassem um alto grau de responsabilidade pessoal sobre a sua saúde, frequentemente atrasavam ou adiavam a procura por cuidados formais de saúde. 
Duarte (2010) analisou a utilização transnacional e complementar de serviços de saúde por emigrantes brasileiros de Governador Valadares nos Estados Unidos. Como conclusão da investigação observou que diversos fatores, entre eles as restrições governamentais ao acesso aos serviços de saúde e o alto custo da assistência médica naquele país, faziam com que os valadarenses adiassem a procura de serviços de saúde e buscassem esses serviços quando retornavam ao Brasil ou, quando em férias, visitavam a cidade, o que levou a um aumento da oferta de serviços de saúde privada na cidade de Governador Valadares.

Outros estudos também têm comprovado que o acesso e utilização dos serviços de saúde em contexto migratório são influenciados por diversos fatores, tanto ao nível psicológico e socioeconómico individual, como ao nível coletivo, e também pelas políticas dos países que acolhem imigrantes.

\section{Metodologia}

A pesquisa aqui relatada é exploratória, descritiva e transversal e utilizou metodologia multi-método para a análise dos dados recolhidos. Foi construído um inquérito, com questões fechadas e abertas o qual foi utilizado em contexto de entrevista, que abordou diversos aspectos, tais como elementos sociodemográficos, sobre o processo migratório, sobre as condições habitacionais e laborais, sobre as condições de saúde, estilos de vida e qualidade de vida. Os resultados foram apresentados através de estatística descritiva para as

questões fechadas e para análise das questões abertas foi utilizada a técnica de análise de conteúdo temática de Bardin (1977). Neste texto serão apresentados alguns dos resultados encontrados na investigação.

Entre os critérios de inclusão na amostra destacam-se: ser brasileiro, com idade igual ou superior a 18 anos; residir em Portugal há pelo 
menos um ano; e concordar em participar da pesquisa. Para cumprir os critérios éticos da pesquisa, os participantes foram informados verbalmente e através de um termo de esclarecimento por escrito sobre a pesquisa, garantindo-se o anonimato e a confidencialidade das informações. Os inquéritos foram realizados durante os meses de julho de 2009 a junho de 2011.

\section{Principais Resultados e Discussão}

A amostra é não probabilística e foi constituída por 120 imigrantes brasileiros, 53 homens e 67 mulheres, com idades compreendidas entre os 19 e os 64 anos (média = 30,8) indicando um grupo maioritariamente jovem. Quanto ao estado civil, 45\% eram solteiros, $47,5 \%$ casados ou viviam em união consensual e $7,5 \%$ eram divorciados. Os principais estados de origem dos imigrantes entrevistados foram Minas Gerais (29,2\%), Paraná (14,2\%) e São Paulo (11,7\%). Quanto à escolaridade, 51,7\% da amostra tem o ensino médio completo, $10,8 \%$ tem ensino superior completo e $12,5 \%$ tem pós-graduação. Os motivos que levaram esses homens e mulheres a emigrar são diversos, tais como os fatores económicos, académicos, matrimoniais e de reagrupamento familiar, entre outros.

Os inquiridos foram questionados se tinham alguma doença crônica. Através dos resultados foi possível constatar uma amostra maioritariamente saudável onde apenas 13 dos 120 participantes relataram alguma doença crônica sendo 9 mulheres e 4 homens. As doenças crónicas relatadas pelos homens foram: alergia respiratória (um indivíduo), diabetes (um indivíduo) e hipertensão (dois indivíduos). Entre as mulheres, quatro eram hipertensas, três relataram problemas alérgicos, uma tinha diabetes e outra tinha problemas crônicos de circulação sanguínea. Na investigação realizada por Dias et al (2008) os autores verificaram que as doenças crónicas que afetam 
mais frequentemente as comunidades imigrantes são a hipertensão arterial (13,1\% para os imigrantes e $18,6 \%$ para os portugueses) e a diabetes (2,8\% dos imigrantes e $6,1 \%$ dos portugueses).

Quanto à percepção sobre o estado de saúde, os resultados mostram que $11,7 \%$ do total dos participantes considerou a sua saúde atual muito boa; $62,5 \%$ boa; $22,5 \%$ regular; $3,3 \%$ má. $\mathrm{Na}$ análise dos resultados por género, $81,1 \%$ dos homens consideraram a sua saúde muito boa ou boa e 18,9\% regular. Em relação ao género feminino, $68,6 \%$ das mulheres consideraram a saúde muito boa ou boa, $25,4 \%$ regular e $6 \%$ ruim. Os resultados encontrados vão de encontro ao descrito na literatura nacional e internacional sobre o estado de saúde percebido, sendo observado uma pior avaliação do estado de saúde por parte das mulheres. Embora a amostra não seja representativa, comparando os dados desta amostra com a percepção sobre o estado de saúde dos brasileiros residentes no Brasil relatados no estudo VIGITEL (Brasil-MS, 2012), os imigrantes entrevistados consideravam-se com um estado de saúde melhor com nenhum homem a relatar um estado de saúde ruim. Quando comparados com imigrantes em geral no estudo de Dias et al (2008) os brasileiros participantes desta investigação apresentam melhor percepção sobre o seu estado de saúde comparativamente ao grupo de imigrantes e também dos cidadãos portugueses. Este fato poderá ser explicado pelo fato de serem imigrantes essencialmente jovens e saudáveis, que não relatam existência de doenças crônicas e, uma parte deste grupo, sendo imigrantes económicos.

Também foi possível observar que a condição de imigrante vivenciada pelos inquiridos influenciou a percepção sobre os fatores que influenciam e afetam a saúde dos indivíduos entrevistados. Os participantes foram questionados sobre quais os fatores que consideram que podem afetar a saúde das pessoas. Os resultados demonstram as crenças que os indivíduos têm relativamente aos 
fatores que podem comprometer a sua saúde, crenças essas influenciadas pelo contexto social de inserção dos indivíduos e construídas social e culturalmente. No que diz respeito aos principais fatores percebidos e relatados pelos imigrantes entrevistados como elementos que afetam a sua saúde destacamos os hábitos alimentares citados por 48 indivíduos, o estresse, a ansiedade, a depressão (29 indivíduos), o tabagismo (28), as condições de trabalho (28), o consumo de bebidas alcoólicas (19) e o fato de fazer ou não fazer prevenção em saúde (10).

Nos dias atuais, os comportamentos relacionados à saúde também denominados de "estilos de vida" são amplamente divulgados como fatores que afetam a saúde ou seja, são fatores determinantes da saúde. Os comportamentos relacionados à saúde incluem o tabagismo, o consumo de bebidas alcoólicas, a prática de exercícios/atividade física e o consumo alimentar. Estes fatores estão relacionados e contribuem para o desenvolvimento de doenças crônicas juntamento com fatores biológicos/genéticos, psicológicos e sociais. Estilos de vida pouco saudáveis como ter uma má alimentação, o tabagismo e o consumo excessivo de bebidas alcoólicas surgiram e foram frequentes nas falas dos entrevistados. Contudo certos fatores da vida diária de muitos imigrantes, muitas vezes em situação irregular, as condições de trabalho encontradas (normalmente com carga horária excessiva e sentimento de abuso e exploração) também fizeram com que alguns dos inquiridos relatassem também o estresse, a ansiedade e depressão como fatores que afetam a sua saúde. Foi também citado por esses brasileiros o fazer (ou não) prevenção em saúde como fator considerado importante que influencia a saúde dos imigrantes brasileiros entrevistados.

Foram igualmente importantes as referências ao estresse, ao estilo de vida e às adversas condições de trabalho, condições e limitações sentidas e expressas pelos participantes da pesquisa. Nas falas dos 
entrevistados foi possível verificar as vivências e vulnerabilidades em contexto migratório como fatores percebidos que influenciam a sua saúde. A título de exemplo citamos alguns entrevistados que disseram "Eu acho que o estresse, a ansiedade, o cansaço, a falta de convívio social e os problemas emocionais e financeiros podem afetar a minha saúde" (mulher, 38); "Eu acho que o clima, o excesso de trabalho, o estresse constante que a gente vive e a má alimentação, sem horários, pode sim afetar a minha saúde" (mulher, 30); "Eu penso que a mudança de clima, a má alimentação e em horários inadequados e, ainda a carga excessiva de horas de trabalho" (homem, 32); “Os maus hábitos, o sedentarismo involuntário e até mesmo o excesso de trabalho sem tempo para o lazer fazem mal à saúde” (homem, 25).

Os participantes também foram questionados se consideravam que viver em Portugal poderia afetar a sua saúde, e verificamos que 77 pessoas $(64,2 \%)$ acreditavam que não. Entre os 43 participantes que acreditavam que poderiam ter problemas de saúde por viverem neste país, os fatores mais referidos foram o tipo e o excesso de trabalho (11), o clima (11), o estresse constante (6), as dificuldades de adaptação (5) e a má alimentação (4).

Nas falas desses entrevistados destacámos: "Eu acho que sim, por causa do excesso de trabalho, do clima e do stresse constante que a gente vive aqui" (mulher, 33); "Aqui mal temos tempo de comer, dormir e descansar. Aqui apenas trabalhamos, trabalhamos” (mulher, 21); "A diferença climática pode me causar alguns resfriados e problemas respiratórios" (homem, 28); "Por causa do estresse constante e também problemas alimentares. A alimentação aqui é muito gordurosa e faz mal ao coração" (mulher, 26); "Penso que minha saúde pode piorar por falta de tempo de descanso e por causa da exploração no trabalho" (homem, 23). 
Quanto ao acesso e utilização dos serviços de saúde, foi possível verificar que houve diferenças quanto ao género e aos motivos de procura dos serviços de saúde. No total das mulheres entrevistadas 46 (68,7\% das mulheres) relatam ter procurado os serviços de saúde para consultas de rotina/prevenção/ginecologia, enquanto outras 20 mulheres $(29,9 \%)$ informaram ter procurado atendimentos de urgência. Quanto ao género masculino, a procura por consultas de rotina verificou-se em 26 casos (49,1\% dos homens) e os que procuraram atendimentos de urgência foram 23 participantes (43,4\% dos homens). São os homens que mais procuram os serviços de urgência, enquanto as mulheres fazem mais consultas de rotina.

Nesta investigação os imigrantes também foram questionados sobre a frequência com que faziam consultas médicas preventivas no Brasil e em Portugal. Para esses indivíduos entrevistados a procura de serviços de saúde com objetivos de prevenção foi afetada pelo contexto migratório. Para os homens houve um aumento da percentagem de indivíduos que em contexto migratório não procuram serviços preventivos. Somavam $30,2 \%$ os que não faziam prevenção quando viviam no Brasil e passou para 67,9\% em Portugal a percentagem de homens imigrantes brasileiros que nunca procuraram os serviços de saúde para prevenção. Passou de 45,3\% (Brasil) para 20,8\% (Portugal) a percentagem daqueles que dizem procurar anualmente os serviços preventivos de saúde. Entre as mulheres brasileiras imigrantes, a percentagem de mulheres que nunca fazem exames preventivos passou de $23,9 \%$ no Brasil para 49,3\% em Portugal. Aquelas que dizem ir anualmente ao médico para prevenção diminuiu de $65,7 \%$ no Brasil para $40,3 \%$ em Portugal.

Tal como já referido anteriormente (Reis \& Ramos 2010, 2012), foi possível verificar que houve uma maior procura por serviços de saúde ao nível dos serviços de urgência, principalmente no género masculino e uma diminuição na procura de serviços de saúde com fins 
preventivos, tanto no género masculino quanto no feminino. Estes resultados vão ao encontro de outros estudos com populações migrantes que acentuam que os migrantes enfrentam mais limitações a serviços e bens que promovem a saúde e previnem a doença, apresentando mais dificuldades de acesso aos serviços de saúde recorrendo, por exemplo, mais aos serviços de urgência e menos aos cuidados de prevenção e rastreio (Ramos, 2004, 2008, 2009).

$\mathrm{Na}$ análise das entrevistas quanto ao modo de utilização dos serviços de saúde, foi possível verificar também, em alguns casos, uma utilização mista transnacional de serviços de saúde, principalmente no caso de cirurgias eletivas ou seja, aquelas não urgentes onde o paciente pode escolher quando realizar a cirurgia, por exemplo, no caso de cirurgias estéticas, remoção de cistos mamários ou miomas uterinos. Nestes casos algumas mulheres brasileiras que necessitaram de realizar cirurgias de miomas ou cirurgias estéticas realizavam os exames e análises sanguíneas em Portugal e a cirurgia no Brasil, com um profissional de sua confiança ou indicado por alguém de sua confiança. Foi observado igualmente que, havia uma utilização transnacional de serviços de saúde quando havia capacidade económica para o efeito. Brasileiros que tinham a oportunidade de ir ao Brasil regularmente, procuravam manter as suas rotinas preventivas no país de origem, demonstrando a importância dos fatores culturais, comunicacionais e afetivos na procura por serviços de saúde e na resolução de problemas nesta área, sendo importante uma boa comunicação em saúde e cuidados culturalmente competentes (Ramos, 2012).

\section{Considerações Finais}

As migrações internacionais provocam alterações no contexto de integração biopsicossocial dos indivíduos migrantes e, para além das capacidades individuais de adaptação dos imigrantes ao novo contexto, 
este novo meio será decisivo para os comportamentos relacionados à saúde que os imigrantes irão adotar. A condição em que vive o imigrante influenciará a percepção que o mesmo terá sobre o meio em que vive, sobre as relações com o Outro e também os seus comportamentos, nomeadamente de saúde no país de acolhimento.

Através da análise das questões de investigação foi possível observar que a perceção que os indivíduos têm sobre os fatores que afetam a sua saúde são direcionados para aspectos negativos ou seja, para os brasileiros entrevistados "um fator que afeta a saúde" é um fator que afeta a saúde negativamente, ou seja, piora o estado de saúde.

Os principais resultados indicaram que as modificações no contexto psicossocial e o contexto em que os homens e mulheres imigrantes estão inseridos influenciaram as percepções, as representações, as vivências e as práticas sobre saúde e doença que os imigrantes brasileiros residentes na região de Lisboa e que participaram desta pesquisa experienciam no seu dia-a-dia em Portugal.

Faz-se necessário aumentar a informação direcionada aos imigrantes quanto aos seus direitos, nomeadamente quanto à saúde, com o objetivo de uma melhor adaptação e integração destes indivíduos no país de acolhimento, e trabalhar em prol da promoção da saúde e da prevenção das doenças crônicas não transmissíveis, atualmente muito prevalentes no mundo, nas populações migrantes e autóctones.

As sociedades multiculturais do mundo global e interdependente de hoje necessitam de uma nova abordagem multidimensional, inter/multidisciplinar e sociopolítica para as populações migrantes e nacionais, para os grupos minoritários e maioritários, que incorpore a dinâmica da pluralidade cultural e os princípios fundamentais dos direitos humanos, em estratégias e políticas que promovam a saúde, a inclusão, a igualdade de oportunidades e o pleno acesso à cidadania de todos. 


\section{Referências}

BARDIN, Laurence. Análise de Conteúdo. Lisboa: Edições 70, 1977.

BRASIL. Ministério da Saúde-MS. Vigitel Brasil 2011: vigilância de fatores de risco e proteção para doenças crónicas por inquérito telefónico. Série G. Estatística e Informação em Saúde. Brasília, DF: MS, 2012. Disponível em: <http://portalsaude.saude.gov.br/portalsaude/arquivos/pdf/2012/Abr/10 /vigitel_100412.pdf>. Acesso em: 3 outubro 2012.

BRASIL. Ministério das Relações Exteriores-MRE. Brasileiros no Mundo - Estimativas. Brasília, DF: MRE, 2011. Disponível em: <http://www.brasileirosnomundo.itamaraty.gov.br/acomunidade/estimativas-populacionais-dascomunidades/Brasileiros \%20no\%20Mundo\%202011\%20\%20Estimativas\%20-\%20Terceira\%20Edicao\%20-\%20v2.pdf $>$. Acesso em: 8 novembro 2011.

CABRAL, Manuel Villaverde (coord.). Saúde e Doença em Portugal. Lisboa: Imprensa de Ciências Sociais, 2003.

CARBALLO, Manuel; DIVINO, José Júlio; ZERIC, Damir. Migration and health in the European Union. Tropical Medicine \& International Health. 1998. Vol. 3. $\mathrm{N}^{\mathrm{o}}$ 12. Disponível em: <http://onlinelibrary.wiley.com/doi/10.1046/j.13653156.1998.00337.x/pdf>. Acesso em: 5 dezembro 2012.

CASA DO BRASIL DE LISBOA-CBL. A $2^{\mathbf{a}}$ vaga de imigração brasileira para Portugal (1998-2003). Estudo de opinião a imigrantes residentes nos distritos de Lisboa e Setúbal. Lisboa: CBL, 2004.

DIAS, Carlos Matias; PAIXÃO, Eleonora; BRANCO, Maria João; FALCÃO, José Marinho. A saúde dos imigrantes. Inquérito Nacional de Saúde 2005-2008. Relatório. Departamento de Epidemiologia. Lisboa: Instituto Nacional de Saúde Dr. Ricardo JorgeINSA, 2008.

DIAS, Sónia; GONÇALVES, Aldina. Migração e Saúde. In Revista Migrações: Revista do Observatório da Imigração. Imigração e Saúde. No1. Lisboa: ACIDI, 2007.

DUARTE, Norberto de Almeida. A utilização transnacional e complementar de serviços de saúde por emigrantes de Governador Valadares-MG nos Estados Unidos e no Brasil. Dissertação de Mestrado em Administração de Empresas - Administração em Saúde, 
2010.

Disponível

em:

<http://bibliotecadigital.fgv.br/dspace/bitstream/handle/10438/4880/61 080100036.pdf? sequence=1>. Acesso em: 11 novembro 2011 .

INSTITUTO BRASILEIRO DE GEOGRAFIA E ESTATÍSTICA (IBGE). Censo Demográfico 2010. Características da População e dos Domicílios. Resultados do Universo. Rio de Janeiro: IBGE, 2011. Disponível

em: <http://www.ibge.gov.br/home/estatistica/populacao/censo2010/caract eristicas_da_populacao/resultados_do_universo.pdf $>$. Acesso em: 29 outubro 2012.

MACHADO, Igor José de Renó (org.). Um Mar de Identidades. A Imigração Brasileira em Portugal. São Carlos-SP. EdUFSCar, 2006.

Reflexões sobre a imigração brasileira em Portugal. In Nuevo

Mundo Mundos Nuevos. $\mathrm{N}^{\mathrm{o}}$ 7, 2007. Disponível em: <http://nuevomundo.revues.org/document5889.html>. Acesso em: 17 março 2010.

MESSIAS, DeAnne. K. Hilfinger. Transnational Health Resources, Practices, and Perspectives; Brazilian Immigrant Women's Narratives. Journal of Immigrant Health, Vol. 4, No 4, 2002.

ORGANIZAÇÃO DAS NAÇÕES UNIDAS-ONU (1948). Declaração Universal dos Direitos Humanos. Disponível em: <http://www.prr3.mpf.gov.br/imagens/boletim_info/dudh-onu.pdf>. Acesso em: 29 outubro 2012.

RAMOS, Natália. Psicologia Clínica e da Saúde. Lisboa: Universidade Aberta, 2004.

. (Org.). Saúde, Migração e Interculturalidade. Perspetivas Teóricas e Práticas. João Pessoa: EDUFPB, 2008.

Saúde, Migração e Direitos Humanos. Mudanças -

Psicologia da Saúde. 17 (1), Jan-Jun, 1-11, S. Paulo, 2009.

Interculturalidade e alteridade. Dinâmicas, contextos e políticas. In J. F. Serafim; L. M. B. Toutain; Y. Geffroy (orgs.). Perspectivas em informação visual: cultura, percepção e representação. Salvador: EDUFBA, 2010.

Comunicação em Saúde e Interculturalidade - Perspectivas Teóricas, Metodológicas e Práticas. RECIIS - Revista Eletrónica de Comunicação, Informação e Inovação em Saúde. Rio de Janeiro, (6), 4, 2012. 
REIS, Lyria; RAMOS, Natália. Adaptação e saúde de imigrantes brasileiros em Portugal. In Actas digitais do $1^{\circ}$ Seminário de Estudos sobre Imigração Brasileira na Europa. Promovido pelo Coletivo Brasil-Catalunya-CBC e Associação de Pesquisadores e Estudantes Brasileiros na Catalunya-APEC. Barcelona, p.178-185. Actas digitais. ISBN: 978-84-614-5407-5, 2010.

Imigrantes brasileiros em Lisboa e utilização dos serviços de saúde. In B. Padilha et al. Novas e Velhas Configurações da Imigração brasileira na Europa. Atas do $2^{\circ}$ Seminário de Estudos sobre a Imigração Brasileira na Europa. Lisboa, CIES, IUL, p. 105$111,2012$.

SERRANO-GALLARDO, Pilar; DÍAZ-OLALLA, José; OTERO, Ángel; BOLUMAR, Francisco. Self-Perceived Health among Migrant and Native Populations in Madrid: A Gender Perspective. International Journal of Migration, Health and Social Care. Vol. 5, $\quad \mathrm{N}^{\mathrm{o}}$ 4, 2010. pp. 43-57. Disponível em: <http://dx.doi.org/10.5042/ijmhsc.2010.0231>. Acesso em: 6 Junho 2012.

SERVIÇO DE ESTRANGEIROS E FRONTEIRAS-SEF. Estatística Millennium 2000. Núcleo de Planeamento. MAI. SEF, 2000. Disponível em: 〈http://sefstat.sef.pt/Docs/Rifa_2000.pdf〉. Acesso em: 12 setembro 2012.

$\begin{array}{ccccc} & \text { Relatório de Atividades } & \text { 2006. Imigração, Fronteiras e } \\ \text { Asilo. } & \text { SEF, } & 2006 . & \text { Disponível } & \text { em: }\end{array}$ <http://sefstat.sef.pt/Docs/Rifa_2006.pdf>. Acesso em: 13 março 2012.

Relatório de imigração, fronteiras e asilo 2010. Oeiras: SEF, 2011. Disponível em: 〈http://sefstat.sef.pt/Docs/Rifa_2010.pdf>. Acesso em: 4 julho 2012.

Relatório de imigração, fronteiras e asilo 2012. Oeiras: SEF, 2013. Disponível em: <http://sefstat.sef.pt/Docs/Rifa\%202012.pdf>. Acesso em: 4 julho 2013.

SIQUEIRA, Sueli (2008). O retorno na perspectiva de género. Atas da $\mathbf{2 6}^{\mathrm{a}}$ Reunião Brasileira de Antropologia. Disponível em: <http://www.abant.org.br/conteudo/ANAIS/CD_Virtual_26_RBA/gru pos_de_trabalho/trabalhos/GT\%2035/sueli\%20siqueira.pdf>. Acesso em: 12 setembro 2012. 
UNITED NATIONS GENERAL ASSEMBLY-UNGA. International migration and development. Report of the Secretary-General, 2013. Disponível

em: <http://www.un.org/esa/population/migration/ga/SG_Report_A_68_19 0.pdf $>$. Acesso em: 14 janeiro 2014.

ZAMBERLAM, Jurandir; CORSO, Giovanni (orgs.). Emigrantes brasileiros no Paraguai - presença scalabriana. Porto Alegre: Solidus, 2007. 